\title{
O Pacto pela Alfabetização na Idade Certa em Goiás - PNAIC: A Formação em Serviço e seus Desafios
}

\author{
Edna Silva Faria* \\ Amone Inacia Alves**
}

\begin{abstract}
Resumo
Este trabalho resulta da reflexão sobre formação realizada em Goiás, intitulada: Pacto pela Alfabetização na Idade Certa - PNAIC. Essa proposta adveio em 2013, de uma expectativa do Ministério da Educação e Cultura (MEC) em qualificar professores atuantes no ciclo de alfabetização, de modo que fossem capazes de refletir sobre os conceitos, práticas e significados do processo de alfabetizar, contribuindo para um debate de âmbito nacional. No Brasil, a formação de professores alfabetizadores ainda é pífia, impactando sobretudo nos resultados demonstrados. Em Goiás, esse Programa foi responsável pela qualificação de quatorze mil professores alfabetizadores, coordenadores e demais profissionais escolares. Compreendeu-se que, sem o investimento dessa ação, não seria possível a inserção dos alfabetizadores na discussão e na implementação de novas práticas e metodologias. Neste texto, adotando como metodologia a revisão bibliográfica, refletimos como o esclarecimento contribuiu para esse processo, ressaltando o papel da interdisciplinaridade. O Programa utilizou material elaborado especificamente para o PNAIC, portanto este artigo aborda também a perspectiva de interdisciplinaridade adotada na elaboração dos materiais de suporte - os cadernos do PNAIC - e nos materiais de apoio - caixa de jogos e atividades - adotados como auxílio no processo de formação.
\end{abstract}

Palavras-chave: formação em serviço, interdisciplinaridade, PNAIC.

Pacto pela Alfabetização na Idade Certa em Goiás (PNAIC): Training in Process and the Challenges

\begin{abstract}
This article results of a reflection about an experience developed in the State of Goias: Pacto pela Alfabetização na Idade Certa - PNAIC (Pact for Literacy at the Right Age). The Project was created in 2013, by the Ministry of the Education and Culture - MEC with the propose to qualify teachers who work in the circle of literacy, with the purpose to help them to reflect about concepts, practices and the meaning of the process of literacy, giving some contribution to a national debate about the subject. In Brazil, the training of literacy teachers is still poor, which impacts, above all on the results demonstrated. In the State of Goiás, this program was responsible for the qualification of fourteen thousand literacy teachers, coordinators and other school professionals. It was understood that without the investment of this action, it would not be possible to insert the literacy teachers in the discussion and implementation of new practices and methodologies. In this text, and adopting bibliographic revision as methodology, we reflected how enlightenment can contribute to this process, standing out to the interdisciplinarity. The Program used material specifically developed for the PNAIC, so this article also addresses the perspective of interdisciplinarity adopted in the elaboration of support materials - PNAIC notebooks - and the support materials - box games and activities, adopted as support in the formation process.
\end{abstract}

Keywords: training process, interdisciplinarity, PNAIC.

\footnotetext{
* Doutora em Letras e Linguística pela FL/UFG. Professora adjunta da FL/UFG. E-mail: edna_faria@ufg.br.

** Doutora em Educação pela FE/UFG. Professora associada da FE/UFG. E-mail: amoneinacia@gmail.com.
} 


\section{Introdução}

Este trabalho ${ }^{1}$ visa a demonstrar como se desenvolveu o Pacto pela Alfabetização na Idade Certa - PNAIC - em Goiás. Esse Programa foi estabelecido pelo MEC em 2012, pela Portaria $\mathrm{n}^{\mathrm{o}}$ 867, de 4 de julho de 2012, objetivando qualificar os professores alfabetizadores, em atendimento à meta 5 do Plano Nacional de Educação (PNE) e à meta 20, quanto à valorização e capacitação desses profissionais e pela garantia dos direitos de aprendizagem e desenvolvimento.

No Estado de Goiás, os trabalhos iniciaram no ano de 2013, inseridos em um contexto de precariedade de formação dos professores dessa fase do ensino, aliado aos pífios resultados da alfabetização no Estado, cujo índice era de 10,8\% em 2000, diminuindo para 7,3\% na década seguinte. Caberia à Universidade desenvolver a proposta, alinhavando junto às demais instituições formadoras do Estado, Universidade Estadual de Goiás (UEG) e Pontifícia Universidade Católica (PUC), uma proposta de formação que conseguisse dirimir essas questões e fornecesse subsídios para um trabalho mais eficaz e eficiente no âmbito da alfabetização.

Foram firmadas parcerias com duzentos e vinte e quatro municípios, envolvendo secretários municipais de Educação, gestores, professores alfabetizadores e demais profissionais interessados em compreender conceitos, estratégias e metodologias de alfabetizar. Se tratava de uma política inovadora, uma vez que os parceiros envolviam Universidades e não institutos privados, na contratação de empresas que empreendiam essas formações, como era tradição no Estado.

Considerando a relevância do tema para as discussões sobre alfabetização e erradicação do analfabetismo, é objeto deste texto descrever como se deu o trabalho formativo desse Programa, além de apresentar dados sobre o alcance dos resultados nos índices do Estado, principalmente por se tratar de um Programa voltado para a formação continuada.

Embora haja polissemia dos conceitos, entendemos por formação, em Kant (2006), a necessidade do esclarecimento e da moralidade, cuja intenção não se atende ao treinamento e à disciplina. Nesse sentido, coube-nos inquirir se é possível em um curso

\footnotetext{
${ }^{1}$ Este artigo é fruto de uma pesquisa desenvolvida após a realização do processo de formação em serviço na proposta do Pacto pela Alfabetização na Idade Certa - PNAIC. Este trabalho foi apresentado no CONEPI, realizado em 2017, e publicado nos anais do evento. Para esta publicação, foram feitas alterações.
} 
de formação com características particulares como o que propõe o PNAIC avançar em termos conceituais, indo além da perspectiva pragmática de passar metodologias aos professores alfabetizadores, bem como levantar o que desejavam os professores alfabetizadores ao cursarem os módulos de formação do PNAIC.

Diante dessas indagações, foi formulado um questionário de avaliação e entregue aos participantes do Programa para que se posicionassem quanto a essas e a outras perguntas. Portanto, a proposta deste trabalho é apresentar os dados, que são reveladores para se pensar em um Programa de grande abrangência como o PNAIC e o papel da Universidade na construção e no desenvolvimento de uma proposta de formação em serviço.

\section{A escolha de um conceito de formação}

Quando analisamos o perfil do profissional que atua na alfabetização das crianças, partimos do pressuposto de que a alfabetização envolve uma série de aspectos que precisam ser pensados pelo professor, tais como: as concepções de ensino e de aprendizagem, a proposta de formação dos alunos e mesmo o entendimento dos conteúdos a ser ensinados. Além disso, urge a necessidade de compreender quem é esse sujeito que ensina e em quais aspectos ele precisa se guiar, de modo a tornar-se um bom professor ou alfabetizador.

Nesse sentido, entendemos que as licenciaturas, sobretudo a de Pedagogia, nem sempre conseguem ter nos currículos disciplinas que englobem a alfabetização e sua prática como objeto de análise. Por exemplo, na matriz do Currículo de Pedagogia da Faculdade de Educação da UFG, apenas uma disciplina se ocupa da alfabetização e do letramento. O pedagogo formado sente a necessidade de discutir sobre metodologias de alfabetização, muitas vezes acreditando que nesse ponto reside a saída para as suas dificuldades em sala de aula. Não discordamos que o enfoque metodológico seja necessário, mas a compreensão da alfabetização como um fenômeno social, que tem a sua historicidade e está ligada a um trabalho formativo mais amplo, deve ser o início de todo projeto de sociedade e de escola.

Embora a escola seja o lócus privilegiado onde se dá o ensino-aprendizagem, a leitura de mundo precede a leitura escrita e está por toda parte, retomando Paulo Freire, 
nos diversos espaços onde crianças aprendem o tempo todo. Sem querer esbarrar na perspectiva redentorista, o professor que atua nesse nível de ensino participará ativamente da formação das crianças, cabendo-lhe desde o cuidado com as primeiras letras, até o diálogo com a realidade na qual vive. Partindo dessa perspectiva, tomaremos o conceito de formação segundo Kant, a partir do que ele designa como educação moral:

\begin{abstract}
A pedagogia, ou doutrina da educação, se divide em física e prática. A educação física é aquela que o homem tem em comum com os animais, ou seja, os cuidados com a vida corporal. A educação prática ou moral (chama-se prático tudo o que se refere a liberdade) é aquela que diz respeito à construção (cultural) do homem, para que possa viver como um ser livre (KANT, 2006, p. 36).
\end{abstract}

$\mathrm{Na}$ formação da cultura, o diálogo toma como ponto de partida a realidade do aluno e como ponto de chegada outras realidades, cabendo-lhe o papel de apresentar a universalidade. Esse cosmopolitismo é importante para a formação geral, pois envolve o entendimento da cultura como um bem universal e a necessidade constante de humanizarse. Kant (2006) assevera que a educação, no afã de instruir o homem dentro da perspectiva da moralidade, deve produzir a humanidade, seja no trato com as outras pessoas, ou no sentimento. A moralidade se fundamenta nos conceitos da razão pura, pois de acordo com Kant (2006, p. 229) “age de tal maneira que usa a humanidade, tanto na tua pessoa como na pessoa de qualquer outro, sempre e simultaneamente como um fim e nunca como meio". Observamos, nesse excerto, que Kant chama a atenção para o fato de que a finalidade máxima da educação deve ser o entendimento do outro, quanto aos seus valores, desejos e direitos, partindo-se da ideia de alteridade.

Ainda que a lei moral seja transmitida a todos, a razão não age com espontaneidade, sendo necessária a participação de outrem, no caso específico abordado aqui do professor alfabetizador. Contudo a formação humana é um processo que envolve a formação de um "sujeito livre, racional e moralmente bom", mas que se cria a partir de si mesmo, no exercício com o outro. Aí residem os limites, segundo essa visão, do papel do professor.

A formação humana é dividida em duas etapas. Na primeira, o homem é heterônomo, não sendo ainda um ser emancipado, sem a capacidade de emancipar-se, dependente dos outros. Nessa etapa, ele precisa ser disciplinado e instruído, seja pela família, demais instâncias sociais e pela escola, e o investimento da educação deve ser 
contínuo, pois há responsabilidades e riscos no ato de educar. Já na segunda etapa, esse mesmo homem adquire características autônomas, sendo capaz de assumir a sua própria formação. Notamos que Kant (2006, p. 15) valoriza em demasia esse processo, assumindo que o homem torna-se "aquilo que a educação faz dele".

Nesse propósito, a educação moral visa a aperfeiçoar o caráter moral dos educandos, instruindo-os sobre a necessidade de se submeter aos deveres morais. Existe uma lei moral que exige conformidade aos princípios da sociedade, sendo tarefa da educação desenvolver qualidades no sujeito que aprende. O conhecimento é o caminho para que o projeto educativo se desenvolva, pois sem ele não há possibilidades de aperfeiçoamento. Considerando o processo de desenvolvimento, Kant relaciona a educação à arte:

\footnotetext{
A educação é uma arte, cuja prática necessita ser aperfeiçoada por várias gerações. Cada geração, de posse dos conhecimentos das gerações precedentes, está sempre melhor aparelhada para exercer uma educação que desenvolva todas as disposições naturais na justa proporção e de conformidade com a finalidade daquelas e, assim, guie toda a humanidade espécie ao seu destino (KANT, 2006, p. 19).
}

Daí a importância de se relacionar a aprendizagem com o passado, com o vivido, o já realizado na formação de professores, de modo a estimulá-los a refletir sobre as práticas que adotam, sobre as experiências que vivenciam no fazer docente, permitindo que conheçam o processo educativo e suas bases conceituais. Por isso é fundamental que os cursos de formação de professores incidam esforços para o desenvolvimento de práticas envolvendo o conhecimento do passado, do experimentado, do saber empírico, a fim de se construir uma reflexão e um esclarecimento dos usos que foram feitos destes.

Convém pensar em uma formação abrangente, com uma perspectiva de alargar os conhecimentos sobre educação, instrução, formação e infância, porém um curso de graduação, pelo tempo desprendido, não seria capaz de contemplar esse feito. Daí a necessidade da formação continuada, chamada formação em serviço, organizada de forma a capacitar o docente para os desafios do seu trabalho.

\section{A formação continuada: em busca de uma análise interdisciplinar}

O PNAIC proporcionou ações voltadas à formação continuada de professores, uma ação continuada pensada pelo MEC, em conjunto com as Universidades e as 
secretarias de educação, visando a qualificar os professores que atuam na alfabetização, entendendo essa etapa como decisiva na formação das crianças. Por possuir uma perspectiva interdisciplinar, compreendia que o profissional atuante nos anos iniciais da formação desses estudantes deveria dispor de diversos conhecimentos que possibilitassem um alargamento da visão de mundo, considerando o contexto escolar. Sobre interdisciplinaridade entendemos o acordo

de um saber com outro saber, ou dos saberes entre si, numa sorte de complementaridade, de cumplicidade solidária, em função da realidade estudada e conhecida. Nem poderia ser de outra forma, porquanto qualquer conhecimento, o mais abrangente que seja, será sempre parcial, jamais expressando plenamente a verdade do objeto conhecido, muito menos a sua inteireza, amplitude e totalidade (COIMBRA, 2016, p. 72).

Essa visão interdisciplinar necessária nos permite acreditar que a alfabetização sem o diálogo necessário com outras áreas do saber é uma ação inócua, pois afinal, a leitura de mundo, nas diversas áreas de conhecimento, precede a leitura de um texto e, a partir dessa concepção, o professor alfabetizador assume a tarefa de ser o interlocutor dessas diferentes linguagens, contextos e práticas escolares.

A interação é fundamento para que o processo de aprendizagem ocorra, num movimento de troca e partilha entre os pares e, nos dizeres de Fazenda (1995, p. 10) "é uma relação de reciprocidade, de mutualidade, que pressupõe uma atitude diferente a ser assumida diante do problema do conhecimento, ou seja, é a substituição de uma concepção fragmentária para unitária do ser humano".

Uma concepção unitária pressupõe diálogo e abertura para as possibilidades que se apresentam, numa atitude de engajamento, em que se firma um compromisso pessoal em direção ao entendimento, de vivências conjuntas, pautadas na partilha e na integração entre os envolvidos. Observamos no PNAIC que a interdisciplinaridade é um dos pilares norteadores para o trabalho de formação, pois constrói-se e orienta-se a partir da integração, seja no que se refere aos conteúdos, seja no que se refere às ações e atividades propostas e, para que isso ocorra, precisa estar associada a uma prática contextualizada.

Tratar da interdisciplinaridade no contexto escolar pressupõe uma mudança no modo de gestão e de organização das atividades pelo movimento da integração. Fazenda (1995, p. 12) ressalta que a interação é “condição de efetivação da interdisciplinaridade. Pressupõe uma integração de conhecimentos visando novos questionamentos, novas 
buscas, enfim, a transformação da própria realidade, num engajamento comum e coletivo".

Observamos, na constituição conceitual do PNAIC, o esforço por uma ação em rede que é demonstrada e está presente no material produzido, que subsidia e orienta o repertório teórico a ser adotado para a formação dos professores, fato evidenciado quando, no Caderno de Apresentação, afirma-se:

\begin{abstract}
O trabalho com os professores alfabetizadores com este conjunto de cadernos tem a tarefa de ampliar as discussões sobre a alfabetização na perspectiva do letramento, numa abordagem interdisciplinar. O processo de formação privilegia um diálogo permanente e sistemático com a prática docente e com a equipe pedagógica da escola para a garantia dos direitos de aprendizagem e desenvolvimento dos estudantes e para a melhoria da qualidade do ensino público brasileiro (BRASIL, 2015, p. 7).
\end{abstract}

Esse posicionamento demonstra a preocupação de oferecer uma formação pautada na construção coletiva, na troca de saberes, no engajamento dos participantes e na mobilização da comunidade escolar para a garantia dos direitos de aprendizagem dos estudantes. Dessa forma, observa-se que um dos pontos relevantes do PNAIC é o investimento na formação profissional pela prática da reflexividade, a partir da vivência cotidiana das práticas e da compreensão da necessidade de uma retomada dos aspectos teóricos e dos fundamentos do processo de alfabetização e letramento.

A retomada de uma práxis docente reflexiva associa-se à constituição da identidade profissional, uma vez que leva o professor a realizar um exercício constante sobre sua atuação em sala, sobre os conhecimentos que têm, as necessidades e demandas que surgem no dia a dia no contexto escolar e as estratégias adotadas para a resolução dos problemas e das dificuldades apresentadas pelos alunos.

Pensar sobre a própria prática requer um esforço e reconhecimento das competências, habilidades, possibilidades e entraves no exercício docente, com a percepção do movimento de permanente construção profissional, de estar em constante formação. Essa percepção é primordial ao engajamento na atuação e permite que, aos saberes existentes, unam-se outros advindos e adquiridos por meio de estudos, de pesquisas e da atitude de colaboração entre os pares, efetivando a aprendizagem coletiva de todos os envolvidos e a colaboração, conforme destaca o Caderno de Apresentação: 
para além da socialização, trata-se de um elemento fundamental no processo de formação. Através da colaboração, busca-se a formação de uma rede que visa ao aprendizado coletivo, por meio do qual os professores exercitem a participação, o respeito, a solidariedade, a apropriação e o pertencimento (BRASIL, 2015, p. 28).

A percepção de um trabalho organizado em sistema de rede e de colaboração encontra respaldo nos pensamentos de Kant, pois pelo conhecimento e consciência da realidade que o cerca, esse profissional constrói sua própria consciência e realidade, e pode interferir sobre ela, sendo mediador de suas aprendizagens às quais vão se agregando outros saberes, por isso, conforme apontam os cadernos do PNAIC (2015, p. 12) "essa integração não pode ser pensada apenas no nível de integração de conteúdos ou métodos, mas basicamente no nível de integração de conhecimentos parciais, específicos, tendo em vista um conhecer global".

Por muito tempo, as discussões referentes à interdisciplinaridade estiveram direcionadas aos anos finais do ensino fundamental e do ensino médio, porém no que se refere ao PNAIC, pela sua configuração e finalidade, para se realizar um trabalho de alfabetização diferenciado e articulado, o caminho possível se dá somente pelo trabalho interdisciplinar, unindo ao processo de alfabetização o letramento e os conhecimentos e conteúdos dos demais componentes curriculares. Nesse sentido, o material PNAIC coloca como objetivos: a) compreender o conceito de interdisciplinaridade e sua importância no Ciclo de Alfabetização; b) compreender o currículo em uma perspectiva interdisciplinar; c) refletir sobre como crianças e professores avaliam experiências de aulas desenvolvidas em uma perspectiva interdisciplinar; d) conhecer possibilidade do uso da leitura no trabalho interdisciplinar; e) conhecer, analisar e planejar formas de organização do trabalho pedagógico como possibilidades de realização de um trabalho interdisciplinar, mais especificamente, por meio de sequências didáticas e projetos no Ciclo de Alfabetização.

É importante observar que, no histórico do tema da interdisciplinaridade, o sentido inicial atribuído à palavra disciplina - ordem - levou a um entendimento de organização curricular limitada a matérias e conteúdos que seriam trabalhados individualmente, sem conexão com outras áreas do saber, restringindo o conhecimento a blocos constituídos na sua especificidade e de maneira fragmentada e compartimentada. 
Ainda é uma constante no cotidiano das escolas em todo o território nacional a sistematização do processo ensino-aprendizagem na perspectiva fragmentada, embora esteja prevista na LDB $n^{\text {o. }} 5.692 / 71$, nos Parâmetros Curriculares Nacionais e nas Orientações Curriculares Nacionais. Conforme apontam os autores do Caderno 3, muitos professores ainda não sabem como fazer acontecer a interdisciplinaridade e a integração “acreditamos que a mudança de atitude para um trabalho interdisciplinar virá com o compromisso pactuado, integrando todas as dimensões de ensino: a pedagógica; a política; e a institucional", referindo-se a André (2005, p. 28).

Tratar do tema da interdisciplinaridade é repensar o processo de formação docente e as diretrizes que orientam a composição das matrizes, a organização das disciplinas, a seleção dos conteúdos a serem trabalhados durante o curso. Esses elementos interferem diretamente na formação dos professores e não necessariamente lhes oferecem condições de refletirem sobre a própria prática, daí esses profissionais demonstrarem empiricamente que sabem o que é interdisciplinaridade, no entanto, demonstram também a carência de estratégias que subsidiem o planejamento de um trabalho interdisciplinar pautado na integração, na partilha e no engajamento entre os membros da comunidade escolar. Notamos que, no que se refere aos pontos fundamentadores do PNAIC, a crença de que o trabalho interdisciplinar resulta da pactuação estabelecida, porque

a interdisciplinaridade se faz em torno de um processo que envolve a integração e o engajamento de educadores, gerando a interação das disciplinas do currículo escolar não apenas entre si, mas, sobretudo destas com a realidade, com vistas a superar a fragmentação e a formar integralmente os alunos (MENDES, GOMES e SILVA, 2015, p. 11).

Conforme os apontamentos constantes nos cadernos do PNAIC, uma das estratégias para que se efetive e fortaleça a interdisciplinaridade no contexto escolar é a organização do tempo associada ao planejamento coletivo, em que são selecionados os conteúdos e definidas as metodologias mais adequadas para o tratamento daquele conteúdo, assim é fundamental:

pensar na seleção, organização e distribuição de conhecimentos relevantes para que todos os estudantes possam se apropriar deles, a fim de atuarem na mudança de seus contextos como sujeitos autônomos, críticos e criativos. Por serem vistos como meios, e não fins, os conhecimentos devem ser abordados pelos professores em situações dinâmicas e reflexivas, por meio do 
planejamento pedagógico coletivo (MENDES, GOMES e SILVA, 2015, p. 11).

O planejamento pedagógico integrado permite uma troca maior entre os professores, estimulando a prática da partilha de seus saberes e das contribuições individuais para o crescimento do grupo. Esse modo de trabalho requer procedimentos de análise, sistematização e flexibilidade, pois permitem a elaboração de objetivos mais claros e bem definidos, com conteúdos específicos e pertinentes às necessidades dos alunos, possibilitando um aprofundamento do que será estudado no âmbito de cada componente curricular, conforme aponta Cordeiro et al:

é preciso considerar a sala de aula como tempo/espaço de interação. Nela, a relação dialógica entre professores e alunos produz interações sociais que levam ambos a refletir constantemente sobre o conhecimento. E essa reflexão não se dá de forma isolada, pensando-se em cada componente curricular, mas de forma holística, integrada (CORDEIRO et al, 2015, p. 27).

Essa visão é o eixo orientador dos conteúdos presentes e apresentados nos Cadernos de formação disponibilizados aos professores participantes do PNAIC. É pela união e na relação dialógica que se constrói e se efetiva a interdisciplinaridade, pela participação ativa de professores e alunos.

A interação produz um movimento diferenciado no ambiente escolar e as experiências partilhadas por esse movimento fortalecem as relações de mediação entre os pares que, inseridos de maneira ativa na preparação e organização de conteúdos e materiais, são estimulados a agirem ativamente diante dos desafios, a partir de diferentes vivências. Quanto a esse fator, Cordeiro et al ressalta ainda que:

\begin{abstract}
A composição de um planejamento criterioso em relação ao trabalho interdisciplinar com vistas à coerência e à reciprocidade entre os diferentes conteúdos exigirá a definição de objetivos a longo, a médio e a curto prazos, em um movimento cíclico e flexível, o qual promova o redimensionamento das práticas pedagógicas, de forma contínua, formativa e mediadora, garantindo os diferentes direitos de aprendizagem das crianças (CORDEIRO et al, 2015, p. 27).
\end{abstract}

Nesse aspecto, ressalta-se a relevância da relação teoria-prática, ao mesmo tempo em que se prova que é possível, por meio de estratégias interativas, a efetivação de uma boa prática a partir de uma adequada teoria e de um planejamento interdisciplinar, 
envolvendo os sujeitos pertencentes ao ambiente escolar, pelo desenvolvimento de atividades pensadas e desenvolvidas coletivamente.

\section{Considerações finais}

O tema da interdisciplinaridade ainda não se esgotou no ambiente acadêmico e requer um amplo espaço para discussão, contudo é inegável o seu valor no processo de ensino-aprendizagem, uma vez que o diálogo é elemento fundamental para a conexão entre as diversas áreas do conhecimento, sobretudo as que se referem a ações de formação continuada de professores, como se dá no PNAIC.

Tal concepção pode levar o professor alfabetizador a considerar que a interdisciplinaridade como um dos fatores principais em um ação de formação continuada é pensar na concepção de uma prática que valorize a reflexão sobre o fazer docente, possibilitando que assuma uma postura de interlocutor nesse contexto e seja o mediador de práticas escolares mais ativas e concretas pela participação, integração de alunos, docentes e gestores, num movimento permanente e gradativo, transformando a escola em um cenário interativo e de interatividade.

Esse modo de organizar o cotidiano escolar requer de todos uma postura crítica e de abertura diante das várias possibilidades que se apresentam, levando a considerar os fatores tempo, planejamento e execução de modo articulado e contextualizado, a fim de que as diversas áreas do conhecimento estejam agregadas e, por esse motivo, garantam a efetivação dos direitos de aprendizagem das crianças.

Assim, a proposta do PNAIC, no que se refere à percepção de trabalho conjunto, interdisciplinar e de interatividade, parte da proposta de que sejam utilizadas metodologias que envolvam todo o coletivo escolar, a partir de conteúdos definidos coletivamente e que surjam da realidade vivenciada por professores e crianças, a fim de que o processo de alfabetização torne-se mais significativo e aconteça de maneira mais coerente, possibilitando um alcance amplo das condições de aprendizagem nessa fase escolar. 


\section{Referências}

BECKER, S. Kant e a formação humana. Disponível em: www.portalanpedsul.com.br. Acesso em: 25 abr. 2010.

BRASIL. Secretaria de Educação Básica. Diretoria de Apoio à Gestão Educacional. Pacto Nacional pela Alfabetização na Idade Certa. Caderno de Apresentação. Brasília: MEC, SEB, 2015.

Secretaria de Educação Básica. Diretoria de Apoio à Gestão Educacional. Pacto Nacional pela Alfabetização na Idade Certa. Interdisciplinaridade no ciclo de alfabetização. Caderno 03. Brasília: MEC, SEB, 2015.

COIMBRA, J. A. A. Considerações sobre a interdisciplinaridade. Disponível em: http:// www.ft.unicamp.br/vitor/processo-seletivo-2016/texto-avila.pdf. Acesso em: 02 maio 2016 .

CORDEIRO, H. F. B. F et al. Currículo e interdisciplinaridade: a construção de conhecimento de forma integrada. In: BRASIL. Secretaria de Educação Básica. Diretoria de Apoio à Gestão Educacional. Pacto Nacional pela Alfabetização na Idade Certa. Interdisciplinaridade no ciclo de alfabetização. Caderno 03. Brasília: MEC, SEB, 2015. p. 22-33.

FAZENDA, I. C. A. (Org.) A pesquisa em educação e as transformações do conhecimento. Campinas: Papirus, 1995.

KANT, I. Primeira introdução à Crítica do Juízo. (Trad.) Rubens Rodrigues Torres Filho. São Paulo: Abril Cultural, 1974. (Coleção os Pensadores).

KANT, I. O que significa orientar-se no pensamento? In: Fundamentação da Metafísica dos costumes e outros escritos. (Trad.) Leopoldo Holzbach. São Paulo: Martin Claret, 2006.

KANT, I. Sobre a Pedagogia. (Trad.) Francisco Cock Fontanella. 5 ed. Piracicaba: UNIMEP, 2006b.

MENDES, A. B.; GOMES, R.; SILVA, J. S. A interdisciplinaridade no ciclo de alfabetização. In: BRASIL. Secretaria de Educação Básica. Diretoria de Apoio à Gestão Educacional. Pacto Nacional pela Alfabetização na Idade Certa. Interdisciplinaridade no ciclo de alfabetização. Caderno 03. Brasília: MEC, SEB, 2015. p. 09-21. 